\title{
Design methodology for combined production and distribution for domestic hot water and space heating
}

\author{
Ivan Verhaert ${ }^{1, *}$ \\ ${ }^{1}$ EMIB, University of Antwerp, Groenenborgerlaan 1712020 Antwerp, Belgium
}

\begin{abstract}
As local heat demand is reducing due to an increased insulation rate, investing in sustainable heat production becomes less interesting. Nevertheless a substantial demand of heat remains in which the thermal energy needed for the generation of domestic hot water grows relatively in importance. In the last two years standards to size production and distribution systems were revised and methods based on tap patterns were elaborated. Nevertheless, some aspects were not covered yet, e.g. how to deal with decentralized storage and how to use these results and new insights in combined heating systems, taking into account that modifications in standards for both space heating and domestic hot water installations are reducing the oversizing. In this paper, first some critical points of attention due to this evolution are illustrated with a case example. Next it is shown how different rules of thumb often developed by different manufacturers deal with these aspects, but lacking however compatibility with existing standards and/or new insights.

Finally, a methodology is proposed and illustrated how to size distribution and production systems for combined heating systems taking into account central and decentralized storage and different kind of end users. The method can be used to size heating systems in collective housing or in district heating networks.
\end{abstract}

\section{Introduction}

In order to shift to a renewable and emission-free energy supply, district heating and cooling have the potential to reduce local emissions and to offer the necessary flexibility to increase the amount of intermittent renewable energy sources in the overall energy supply[1][2]. Also in collective housing complexes or apartment buildings centralizing the heat generation has scale advantages with respect to the incorporation of renewables or efficient technologies like cogeneration.

As local heat demand reduces due to increasing insulation rate, the latter is even more pronounced. The challenges integrating these technologies have been discussed in [3], pointing out the importance of the hydronic design.

The first step in this design, however, is sizing. Important is that the heat demand needs to be met at all time or with a pre-defined level. This sizing does not only affect the production unit, but affects the entire distribution system.

The requested thermal power needs to be determined at every point in the distribution system to size the pipes based on pressure drop, velocity and chosen temperature regime.

With respect to these design choices, low temperature regimes facilitate higher efficiencies of the boiler or cogeneration plant, better performances of the heat pump and a reduction in distribution losses [4]. Whereas the pipe dimensions offer a hydraulic boundary, limiting flow rate, with respect to maximum velocity and pressure drop. Recently developed software tools like HySopt [5] enable engineers to optimize the interaction between the hydraulics and heat distribution.

However, the heat demand itself is an input and the software illustrates how under sizing is typically solved by increasing temperatures, and reducing overall performance. Whereas on the other hand oversized installations have not only a higher distribution losses and initial investment costs, but also tend to cycle too much, resulting in higher maintenance costs.

Determining the heat demand at any point in the installation is therefore crucial for a successful operation of a collective heating system.

\subsection{Scope and paper outline}

The objective of this paper is to propose and discuss a sizing methodology, offering a transparent and straightforward answer to the design problem for combined heating installations.

With respect to the practical feasibility and the incorporation of future insights in heat demand, this transparency is an important boundary condition to achieve the envisaged goal of the method itself, namely

\footnotetext{
*Corresponding author: ivan.verhaert@uantwerpen.be
} 
properly sized collective heating systems. In a second phase, the hydronic design can be fine-tuned and optimized using software tools. As such tools already exist, this is out of scope of this paper.

Firstly, the overall sizing method is elaborated, discussing the remaining design issues, including some critical reflections on ongoing evolutions. Secondly, a discussion on different standards or rules of thumb, with respect to these issues is provided, including the proposed methodology. To conclude, the proposed methods are compared to the results of a case study

\section{Overall framework for design}

\subsection{The design problem}

Within the Belgian context, today no standard exists to size collective heating systems which provide both domestic hot water and space heating.

Although standards do exist for space heating, domestic hot water installations and pipe diameters.

\subsection{General approach and design philosophy}

The objective of the sizing issue is to determine the heat demand at any point. Since this can be later translated into the proper flow rates with the selection of the temperature regimes.

With respect to existing standards TV 235 and NBN EN 12828 , the heat demand for the downstream distribution network $\left(\mathrm{P}_{\mathrm{TH}, \text { tot }}\right)$ should be equal to the maximum simultaneous heat demand including following needs:

- The thermal power for space heating $\left(\mathrm{P}_{\mathrm{TH}, \mathrm{SH}}\right)$

- The thermal power for preparation of domestic hot water $\left(\mathrm{P}_{\mathrm{TH}, \mathrm{DHW}}\right)$

- The thermal power for other demands ( $\left.\mathrm{P}_{\mathrm{TH}, \mathrm{AUX}}\right)$, including possible heat losses.

The total power for combined heating becomes then:

$\mathrm{P}_{\mathrm{TH}, \text { tot }}=\mathrm{f}_{\mathrm{SH} .} \cdot \mathrm{P}_{\mathrm{TH}, \mathrm{SH}}+\mathrm{f}_{\mathrm{DHW}} \cdot \mathrm{P}_{\mathrm{TH}, \mathrm{DHW}}+\mathrm{f}_{\mathrm{AUX}} \cdot \mathrm{P}_{\mathrm{TH}, \mathrm{AUX}}$

Within residential buildings, $\mathrm{P}_{\mathrm{TH}, \mathrm{AUX}}$, solely depend on the installation design itself. Therefore, for design reasons only the sum of the two first terms need to be determined to establish the boundary conditions.

$$
P_{\mathrm{TH}, \text { tot }}=\mathrm{f}_{\mathrm{SH} .} \cdot \mathrm{P}_{\mathrm{TH}, \mathrm{SH}}+\mathrm{f}_{\mathrm{DHW}} \cdot \mathrm{P}_{\mathrm{TH}, \mathrm{DHW}}
$$

Based on this formula two design questions arise:

- Which methods determining the heat demand exist to size installation for space heating $\left(\mathrm{P}_{\mathrm{TH}, \mathrm{SH}}\right)$ and domestic hot water $\left(\mathrm{P}_{\mathrm{TH}, \mathrm{DHW}}\right)$ ?

- Which method can predict the combined heat demand with respect to comfort and energy efficiency? Or if both $\mathrm{P}_{\mathrm{TH}, \mathrm{DHW}}$ and $\mathrm{P}_{\mathrm{TH}, \mathrm{SH}}$ are known, what rules can be applied to determine the possible reduction factors $f_{\mathrm{DHW}}$ and $\mathrm{f}_{\mathrm{SH}}$ (between 0 and 1 ), based on the chance of simultaneous occurrence.
The second design question is the main topic of this paper and is elaborated in Section 3. In order to understand the boundary questions related to this design question, however, a brief discussion on the first question is necessary.

"Which methods exist to determine heat demand for space heating and for domestic hot water generation?"

\subsubsection{Space heating}

For space heating different standards exist. Typically the design power for a building (or combination of buildings), $P_{T H, S H}$, is the result of the sum of heat demands of all connected living units, as a high simultaneity can be assumed (see below).

The latter depends highly on how the design power for each unit is determined. Conventionally, each unit (index i) is characterized by transmission losses $\left(\mathrm{P}_{\mathrm{TH}, \mathrm{Ti}}\right)$ ventilation losses $\left(\mathrm{P}_{\mathrm{TH}, \mathrm{Vi}}\right)$ and reheating power $\left(\mathrm{P}_{\mathrm{TH}, \mathrm{RHi}}\right)$. In this case, the overall heat demand for space heating is typically given by Eq.2.

$$
P_{T H, S H}=f_{T} . \Sigma P_{T H, T i}+f_{V} \cdot \Sigma P_{T H, V i}+f_{R H} \cdot \Sigma P_{T H, R H i}
$$

With,

- $\mathrm{f}_{\mathrm{T}}$ a reduction factor taken internal transmission losses into account. For district heating this is 1 , as no heat can be recovered from another unit. Within e.g. an apartment building, this will be $<1$, as there is normally always a mutual wall or floor/ceiling.

- $f_{\mathrm{V}}$, a reduction factor taken into account that with in/exfiltration only one side of the building and only part of the living units will experience additional ventilation losses. For airtight buildings with mechanical ventilation this variation is negligible ( so $_{\mathrm{v}}=1$ ).

- $\mathrm{f}_{\mathrm{RH}}$, the simultaneity factor for reheating $(<1)$. It is statistically unlikely all units are reheated simultaneously during a strong winter day.

The above presented standard starts from a worst-case approach in which no heat gains are contributing. In this way, the standard guarantees sufficient heat at any time.

However, due to an increased insulation rate, the relative importance of heat gains is rising. This is illustrated in Figure 1 in which the heat losses and gains for a small one-family building is represented for an average insulated building (left) and a well-insulated building (right). The purple and outer line represent the transmission and ventilation losses, whereas the green and yellow graphs represent the reduction by internal and solar heat gains.

The requested thermal power is shown in the lower graphs, whereas the presence of the peak is due to the power needed for reheating as the chosen control in this example included temperature reduction at night.

Within the present standard EN12831-1, the inclusion of these gains, $P_{T H, G i}$, are foreseen, Eq3.

$P_{T H, S H}=f_{T} . \Sigma P_{T H, T i}+f_{V} \cdot \Sigma P_{T H, V i}+f_{R H} \cdot \Sigma P_{T H, R H i}-f_{G} . \Sigma P_{T H, G i}$ 

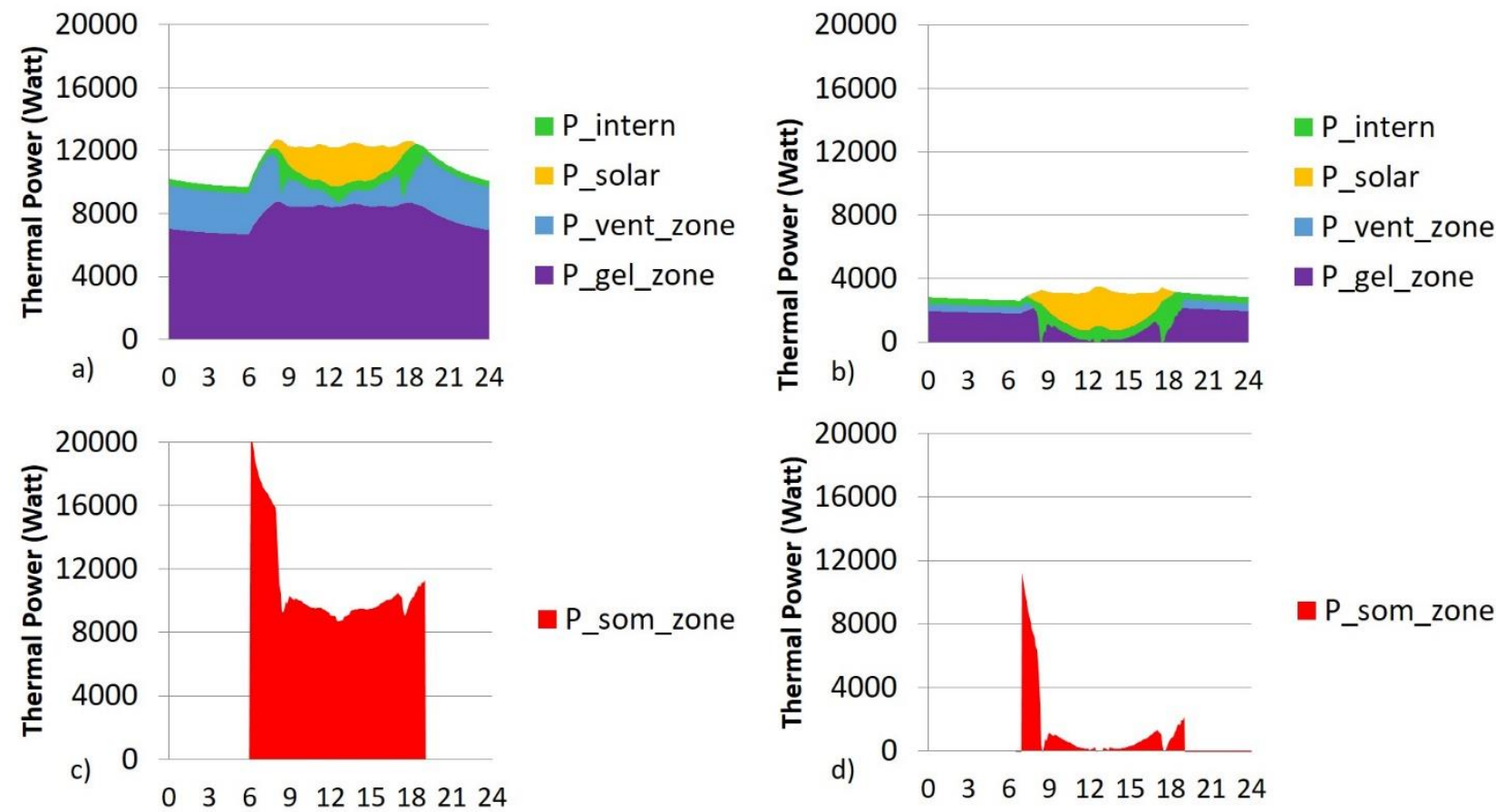

Fig. 1 Graphical representation of the heat losses and gains during an average winterday for in a poorly (a) and (b) well-insulated dwelling, and the corresponding net heat demand (c) and (d) to maintain set point temperature.

However, the practical determination of these heat gains and their simultaneity are still unclear and subject of ongoing research [6].

\subsubsection{Domestic hot water}

Besides space heating domestic hot water generation is the main end use for heating in building and growing in relative importance as it remains relatively fixed while other heat demands are decreasing.

With respect to sizing hot water installations earlier a methodology based on tap patterns is proposed [7].

The result is that for each combination of tap ends or dwelling, $i$, a series of $j$ thermal powers, $P_{S W W i, j}$, and linked storage volumes $V_{S W W i, j}$, exists.

Typically, for a number of dwellings or a large apartment building the necessary thermal power and volume is lower than the sum of the needs in the different dwellings or apartments, as it is statistically unlikely that all tap ends will be used simultaneously.

Based on new insights, out of measured and simulated data[8], standards to size domestic hot water installations, both production as distribution, were recently adjusted or will be adjusted.

\subsubsection{Additional reflections with respect to designing more complex combined systems}

Besides the sizing issues, complementarity or transparency discussed earlier, also combined systems with a partially separate domestic hot water loop integrated on a heating grid or decentralized storage pose additional design problems, which have not been addressed within existing standards.

\section{Review of existing standards or rules of thumb for combined systems}

In order the second design question, posed in 2.2.2., a review is presented on the different rules used in the Belgian context by different engineering offices. "Which methods exist to determine the combined heat
demand?"

Although many variations exist, three main categories can be distinguished, namely calculating the sum (all $\mathrm{f}=1$ ), calculating the maximum of $\left(\mathrm{P}_{\mathrm{TH}, \mathrm{SH}} ; \mathrm{P}_{\mathrm{TH}, \mathrm{DHW}}\right)$ or mixed methods, including substation dependent calculation rules.

The variations in each category are often the result on the methods chosen answering the first design question.

\subsection{Full summation approach}

Theoretically, and to ensure sufficient thermal power, the most straight forward approach is to calculate the total heat demand both for space heating and for domestic hot water generation and to summate this.

$$
P_{T H, t o t}=P_{T H, S H}+P_{T H, D H W}
$$

As long no standard exist, this method offers the best guarantee that there is no under sizing, but as can be expected, this method results often in oversized installations, especially with the previous sizing rules for domestic hot water installations.

\footnotetext{
* Corresponding author: ivan.verhaert@uantwerpen.be
} 
With the revised standards for domestic hot water systems and with alternative calculations ignoring reheating power, some trial-and-error approaches exist, but not satisfying the objective of a transparent and generic approach, which works in all cases. E.g. for applications with a low number of dwellings or apartments and low needs for domestic hot water, it is easily understood it will be under sized as the relative importance of reheating power is big and independent of domestic hot water use. Besides, in large buildings still some over sizing can occur.

\subsection{Maximum approach}

With the original and officially still present design standard for domestic hot water, a common practice in Belgium was to use at each point in the network the maximum out of both heat demands. This was often applied in systems with a substation without any local storage in order to size the piping network.

$$
P_{T H, t o t}=\max \left(P_{T H, S H} ; P_{T H, D H W}\right)
$$

However, with the evolution of both design rules in mind and specifically in cases where the difference between the thermal power for space heating does not differ that much from the power for domestic hot water generation, under sizing problems arise. Some engineering offices solved this by adding $20 \%$, based on experience. In general, this offered good results, but did not solve the issue of transparency and can only be acceptable with sufficient proof on a large and also more diverse set of apartment buildings.

\subsection{Method based on type of substation}

It is clear the first method seems to be oversized. Whereas the second method risks under-sizing in a cold winter when hot water is tapped. The following methods try to find a balance, and are often or variation of the two first approaches.

\subsubsection{Simultaneity factors for substation with direct heat exchangers}

This method is based on summation, although the demand for domestic hot water is based on a simultaneity factor at the level of the substation. The method is developed for substations with direct heat exchangers and published in a report [9]. The calculation method starts from a heat demand according to EN 12831 and calculates the necessary demand for domestic hot water based on the available additional heat for domestic hot water, $\mathrm{Q}_{\text {sub,DHW,i }}$ multiplied with the number of substation and a

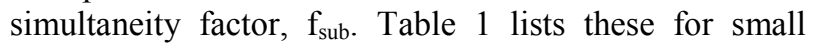
apartment buildings, whereas Eq. 6 illustrates this for larger buildings.

$$
f_{\text {sub }}=\frac{0.8}{\sqrt{3 n-1}} \text { with } n: \text { number of apartments }
$$

Table 1 Simultaneity coefficient for substations

\begin{tabular}{|c|c||c|c|}
\hline Number of substations & fsub & Number of substations & fsub \\
\hline 1 & 1 & 8 & 0,176 \\
\hline 2 & 0,529 & 9 & 0,162 \\
\hline 3 & 0,372 & 10 & 0,152 \\
\hline 4 & 0,293 & 11 & 0,145 \\
\hline 5 & 0,246 & 12 & 0,136 \\
\hline 6 & 0,215 & 13 & 0,130 \\
\hline 7 & 0,192 & 14 & 0,125 \\
\hline
\end{tabular}

The drawback of the method is the dependency on the chosen type of substation, as it only works with similar substations. Besides this disadvantage, new insights in determination of the heat demand for space heating or domestic hot water cannot be easily integrated in het sizing method.

\subsubsection{Adjustment factors for substation with storage}

A second method in the report[9] is developed for substations with storage. This method follows the maximum approach, but uses different partial demands. The basic idea here, is that the maximum is taken out of the demand for space heating $\left(P_{T H, S H}\right)$, adjusted with some corrections $(+1 \mathrm{~kW})$ and $(+5 \%)$ and the summated demand to load all boilers.

$$
\begin{aligned}
& P_{T H, t o t}=\max \left(P_{T H, S H} ; P^{*}{ }_{T H, D H W}\right) \\
& P^{*}{ }_{T H, S H}=n .\left(P_{T H, S H, i}+1 \mathrm{~kW}\right) \cdot 1,05 \\
& P^{*}{ }_{T H, D H W}=n .\left(P_{S u b, D H W, i}\right) \cdot 1,05
\end{aligned}
$$

For large buildings ( $>20$ app) a simultaneity factor is introduced as well, applied on the summated demand to load the boilers. For small buildings, $\mathrm{f}_{\text {sub }}=1$.

Table 2 Simultaneity factor for substations with storage

\begin{tabular}{|c|c|c|c|c|c|c|}
\hline n & 20 & 30 & 50 & 75 & 100 & 200 \\
\hline fsub & 0.4 & 0.36 & 0.31 & 0.29 & 0.27 & 0.24 \\
\hline
\end{tabular}

Both methods depend on type of substation and prevents a generic and transparent approach of the sizing issue. Besides that evolutions or new insights in the determination of the overall space heating and heat demand for domestic hot water cannot be integrated in the sizing method.

\subsection{Mixed method : DeltaQ}

This method[10] is based on the standards DIN4708 and EN12831. It guides the designer to the maximum approach as long this maximum is determined by the domestic hot water demand.

If the demand for space heating is higher and parallel demand is possible the summation approach is used.

Besides this, there are some recommendations to ignore the reheating demand for space heating in parallel mode, unless there is also a charging time foreseen for accumulation within the domestic hot water need. In the latter case, one have to examine whether they interfere.

The last method has the advantage of being compatible with an existing method, but is originally designed for 
central heating system with a separate loop for space heating and for domestic hot water.

Some problems remain within the interpretation, e.g. with decentralized boiler like substations with storage. The recommendation with respect to re-heating, requires interpretation just there, where most questions will arise. In addition, when demand for space heating and domestic hot water are more or less the same, the same remarks as for the maximum and summation approach are applicable.

\section{Suggested design method}

Based on the design discussion in the previous section, two rules are proposed here in order to tackle the remarks made and needs mentioned.

First of all a method to calculate the combined heat demand of an installation at any place, which is transparent and is complementary to existing standards about domestic hot water and space heating. This last condition allows the method, to evolve with new insights, with respect to these sub-demands.

Besides that, it is noticed that decentralized storage in general confuse many designers. For that purpose, also a design rule is suggested.

\subsection{Design of the production and the distribution system with decentralized storage}

As discussed in section 2.2.2 and in [7], $P_{S W W i, j}$, will depend on the foreseen storage volumes $V_{S W W i, j}$. With decentralized storage for domestic hot water, it is sometimes not clear how to size the distribution system upstream.

Following approach is suggested, namely to size it on the maximum demand, $P_{D H W}$, out of two calculation methods:

- The determination of the domestic hot water demand at a certain, $P_{D H W}$, taking the sum of all decentralized storage into account as if that storage volume is foreseen at that position.

- The determination of the domestic hot water demand based on all tap ends, not behind that decentralized volume.

This method is suggested to solve this remaining design issue for complex distribution systems.

\subsection{Method of the maximum sum of parts}

In this method new insights can be easily integrated. The method divides all subsets behind the point investigated, into a group 'space heating' and a group 'domestic hot water', after which a total heat demand is determined for each group. The group name determines how. After that the sum is from both parts is calculated as possible overall heat demand.

Because the way, how the groups are divided is very important here and can vary a lot. E.g. All apartments in group 'DHW' and none in group 'SH' or $50 \%$ each or $10 \%-90 \%$, etc . For this reason, all possible combinations are investigated and the maximum out of these combinations is withheld.
The method is compatible with the 'power-storagemethod' reported in [7]. In this version, next to the variations in group also the variations in storage size can be altered. The net demand will be the projected maximum. In this way a new 'power-storage-curve' similar as for domestic hot water can be generated.

Typically, this curve will have a lower power limit, namely the maximum heat demand for space heating.

\subsubsection{Illustrating example}

For illustrative purposes a simplified case is chosen with 36 identical small dwellings and independent heat demand for space heating $(3.5 \mathrm{~kW})$, with 2.5 persons.

The overall heat demand for space heating is $126 \mathrm{~kW}$, whereas the peak demand for instantaneous domestic hot water consumption is $135 \mathrm{~kW}$.

With this method, we can determine 37 ways to divide the dwellings into two groups, as they are all similar and noninterfering. The method can also be used in more complex settings, resulting in more possibilities.

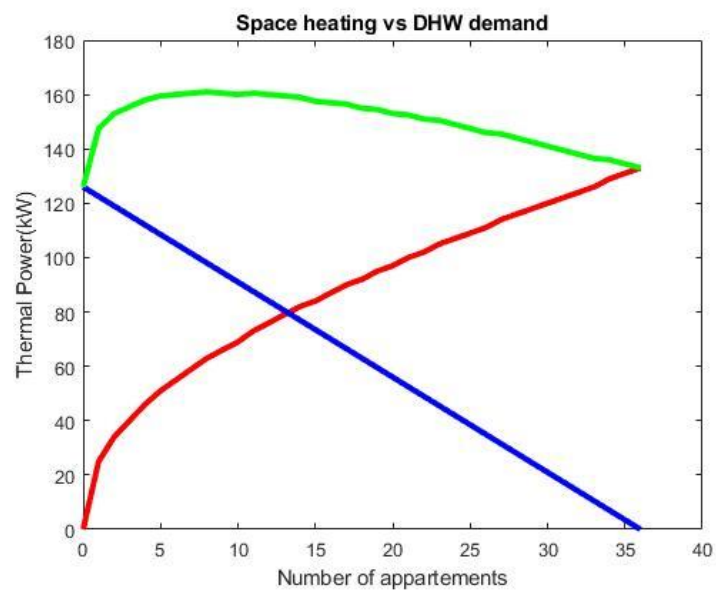

Fig. 2 Necessary heat demand for every group (blue for ' $D H W$ ' and red for ' $S H$ ') including their sum (green) as a function of the number of apartments dedicated to the group ' $\mathrm{DHW}$ '.

In Fig. 2 the $\mathrm{X}$-axis represents the amount of dwellings within group 'DHW', which can be 0 up to 36 . The red line shows the demand for domestic hot water for this group, whereas the blue line show the demand for space heating for the other group in that case. As the sum needs to be taken, the green line represents all possible 'sum of parts', the maximum is about $160 \mathrm{~kW}$.

If for every possibility not only the maximum demand for domestic hot water is determined, but also the powerstorage curve, this results in Fig 3. As can be seen is that from a certain storage size, the power is given by the maximum heat demand for space heating. 


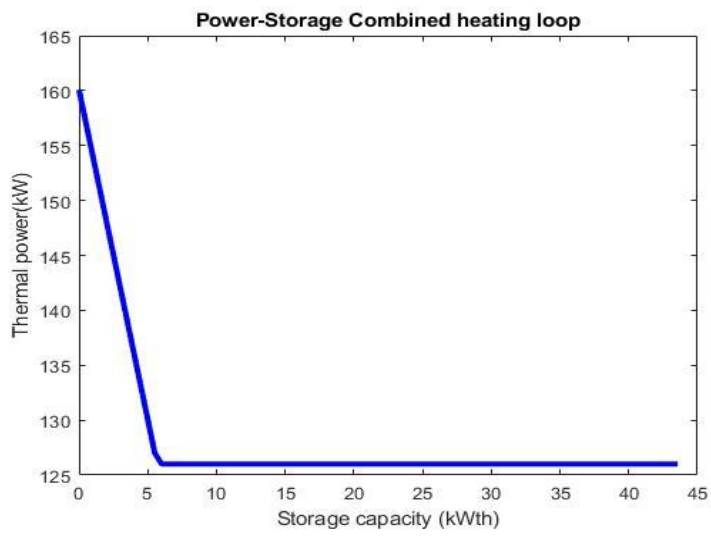

Fig. 3 Power-Storage curve for a combined heating loop

\section{Evaluation}

In order to evaluate the proposed design method, it is compared with data on the heat demand over time from a case study and compared with the other design methods.

\subsection{Validation}

Within [11] an apartment building with combined heating system is simulated, similar to the example discussed in 4.2.1.

From the simulations, it was shown that a boiler of $132 \mathrm{~kW}$ was not sufficient, but a boiler of $158 \mathrm{~kW}$ did meet the demand at all time after a year simulation, when a typical inertia of this boiler was considered.

The results give an indication of the potential, as for interpretation also heat losses of the distribution system need to be calculated. The next step will be to elaborate a sensitivity analysis on the maxima and the comparison with other cases.

\subsection{Comparison}

To get an idea on how the different methods relate to each other they are presented in Figure 4.

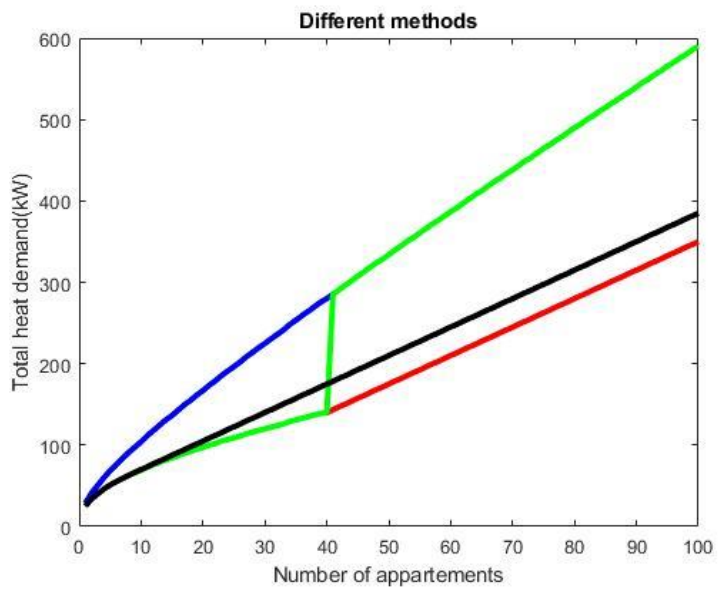

Fig. 4 The total heat demand for a combined heating system (excluding storage) as a function of building size. Red represents the maximum approach, whereas blue the summation and green the DeltaQ. The black line represents the maximum sum of parts.
The maximum approach represents the lower limit, whereas the blue one the summation. Whereas the green line (DeltaQ) is rather disruptive. The black line represents the method discussed in Section 4. It stays about $20 \%$ above the red line, which is in line with the empirical design rule some engineering offices mentioned to be satisfying (See 3.2)

\subsection{Discussion}

The presented evaluation gives an indication of its functional merits. The results are in line with methods showing satisfying results over the complete spectrum. This illustrates the potential.

However, this analysis is not yet proof of its validity. It is the objective of the research group to gather more data out of field tests to validate the method.

\section{Conclusion}

The paper presents an overview of the design issues with combined heating system and the necessity to determine a transparent and future proof approach.

An overview is presented of different rules and standards, of possible solutions, which are discussed briefly, and finally a transparent design method is proposed and put in perspective with other design rules and an illustrative case study.

Based on this first assessment, one can conclude that the rule has definitely potential. Further validation for different case studies will be the next step in this research. Besides the elaboration of the design issues with respect to the determination of the demand on space heating on its own.

\section{Acknowledgment}

The author would like to thank Thomas More Kempen vZW and BBRI, for sharing their results and examples regarding the issues with space heating. Next to these partners also the large consortium of Flemish companies who supported the research with means and feedback.

\section{References}

[1] H. Lund et al., "4th Generation District Heating $(4 \mathrm{GDH})$ : Integrating smart thermal grids into future sustainable energy systems," Energy, vol. 68, pp. 1-11, Apr. 2014.

[2] D. Wang, K. Orehounig, and J. Carmeliet, “A Study of District Heating Systems with Solar Thermal Based Prosumers," Energy Procedia, vol. 149, pp. 132-140, Sep. 2018.

[3] F. Van Riet, E. Janssen, G. Steenackers, and I. Verhaert, "Hydronic design of cogeneration in collective residential heating systems: state-ofthe-art, comparison and improvements," Appl. Therm. Eng., vol. 148, pp. 1246-1257, Feb. 2019.

[4] L. Brand, A. Calvén, J. Englund, H. Landersjö, and P. Lauenburg, "Smart district heating networks - A simulation study of prosumers' 
impact on technical parameters in distribution networks," Appl. Energy, vol. 129, pp. 39-48, Sep. 2014.

[5] F. Van Riet, H. El Khaoui, F. Hulsbosch, G. Steenackers, and I. Verhaert, "Exploring the novel software Hysopt : a comparison of hydronic heat distribution systems of an apartment building," in CLIMA 2016 : proceedings of the 12th REHVA World Congress, 22-25 May 2016, Aalborg, Denmark: volume 3 / Heiselberg, Per Kvols [edit.], 2016, pp. $1-11$.

[6] J. Van der Veken, "Smart Power (project)."

[7] I. Verhaert, B. Bleys, S. Binnemans, and E. Janssen, "A Methodology to Design Domestic Hot Water Production Systems Based on Tap Patterns," in CLIMA2016 - proceedings of the 12th REHVA World Congress, 2016.

[8] I. (UA) Verhaert et al., "TETRA SWW: Richtlijnen voor productie en selectie van sanitair warm waterinstallaties," 2014.

[9] COSTIC, "Guide technique pour la mise en oeuvre des modules thermiques d'appartements," 2016.

[10] DeltaQ, "Dimensionierung von Wärmeerzuegern."

[11] M. De Pauw, F. Van Riet, J. De Schutter, S. Binnemans, and J. Van Der Veken, "A methogology to compare collective heating systems with individual heating systems in buildings," Proc. REHVA Annu. Meet. Conf. Low Carbon Technol. HVAC, no. April, pp. 1-8, 2018. 